\title{
Developmental consequences of perinatal cannabis exposure: behavioral and neuroendocrine effects in adult rodents
}

\author{
Patrizia Campolongo • Viviana Trezza • \\ Patrizia Ratano • Maura Palmery • Vincenzo Cuomo
}

Received: 1 April 2010 /Accepted: 14 May 2010/Published online: 17 June 2010

(C) The Author(s) 2010. This article is published with open access at Springerlink.com

\begin{abstract}
Rationale Cannabis is the most commonly used illicit drug among pregnant women. Since the endocannabinoid system plays a crucial role in brain development, maternal exposure to cannabis derivatives might result in longlasting neurobehavioral abnormalities in the exposed offspring. It is difficult to detect these effects, and their underlying neurobiological mechanisms, in clinical cohorts, because of their intrinsic methodological and interpretative issues.

Objectives The present paper reviews relevant rodent studies examining the long-term behavioral consequences of exposure to cannabinoid compounds during pregnancy and/or lactation.

Results Maternal exposure to even low doses of cannabinoid compounds results in atypical locomotor activity, cognitive impairments, altered emotional behavior, and enhanced sensitivity to drugs of abuse in the adult rodent
\end{abstract}

Patrizia Campolongo and Viviana Trezza contributed equally to the present paper.

P. Campolongo $(\bowtie) \cdot$ P. Ratano $\cdot$ M. Palmery $\cdot$ V. Cuomo

Department of Physiology and Pharmacology,

Sapienza University of Rome,

P.le A. Moro 5,

00185 Rome, Italy

e-mail: patrizia.campolongo@uniroma1.it

V. Trezza

Rudolf Magnus Institute of Neuroscience,

Department of Neuroscience and Pharmacology,

University Medical Center Utrecht,

Utrecht, The Netherlands

V. Trezza

Department of Biology, University Roma Tre,

Rome, Italy offspring. Some of the observed behavioral abnormalities might be related to alterations in stress hormone levels induced by maternal cannabis exposure.

Conclusions There is increasing evidence from animal studies showing that cannabinoid drugs are neuroteratogens which induce enduring neurobehavioral abnormalities in the exposed offspring. Several preclinical findings reviewed in this paper are in line with clinical studies reporting hyperactivity, cognitive impairments and altered emotionality in humans exposed in utero to cannabis. Conversely, genetic, environmental and social factors could also influence the neurobiological effects of early cannabis exposure in humans.

Keywords Cannabis · THC · Pregnancy - Lactation . Development $\cdot$ Neurobehavioral teratology $\cdot$ Learning and memory Anxiety $\cdot$ Stress hormones

\section{Introduction}

Since the identification of the fetal alcohol syndrome (FAS) in the 1970s (Jones and Smith 1973), there has been a dramatic increase in the number of clinical and preclinical reports examining the short- and long-term effects of maternal exposure to drugs of abuse.

While maternal exposure to high doses of alcohol, cocaine, opiates, cannabis, and tobacco results in impaired growth and morphological abnormalities in the offspring (El Marroun et al. 2009; Kosofsky and Hyman 2001; Thompson et al. 2009), low to moderate drug abuse during pregnancy and lactation has also been related to subtle, albeit lasting, postnatal alterations in brain function and behavior. Research into these mostly subtle associations between maternal drug use and offspring neurobehavioral 
alterations utilizes the concepts and methods of neurobehavioral teratology (Coyle et al. 1976; Vorhees 1989).

Over the years, general teratological principles have been modified and extended to research in behavioral teratology, resulting in two major postulates (Vorhees 1989): (1) vulnerability of the central nervous system (CNS) to injury extends throughout the fetal and neonatal periods and beyond the infancy stage, including all aspects of nervous system development (e.g., neurogenesis, neuronal differentiation, arborization, synaptogenesis, functional synaptic organization, myelination, gliogenesis, glial migration, and differentiation), and (2) the most frequent manifestation of injury to the developing CNS does not result in nervous system malformations, but rather in functional abnormalities that may not be detectable at birth.

In recent years, both clinical and preclinical studies have shown that exposure to cannabis preparations during pregnancy and lactation can induce behavioral teratogenic consequences (Campolongo et al. 2009b; Fried 2002; Fried and Smith 2001; Huizink and Mulder 2006; Navarro et al. 1995; Schneider 2009; Trezza et al. 2008b); indeed, the main psychoactive component of cannabis, $\Delta 9$-tetrahydrocannabinol (THC), can cross the placenta during gestation, and be secreted in the maternal milk during lactation (Hutchings et al. 1989; Jakubovic et al. 1977).

Studies on the long-term behavioral abnormalities induced by maternal cannabis exposure are of special relevance, for two main reasons. First, nowadays cannabis preparations are among the illicit drugs most widely used by pregnant women in Western countries (Fried and Smith 2001); for instance, the self-reported use of cannabis during pregnancy is approximately $2.9 \%$ in the United States (Huizink and Mulder 2006), and reaches 5\% in the United Kingdom (Fergusson et al. 2002). Second, since the endocannabinoid system is present and already functional in early pregnancy (Fernandez-Ruiz et al. 2000; Fride 2008; Harkany et al. 2007), the active ingredients of cannabis and their metabolites could directly affect the brain by altering endocannabinoid signaling and related neurotransmitter and neuroendocrine systems.

A common problem in neurobehavioral teratology is that the identification of subtle neurodevelopmental phenotypes after exposure to drugs of abuse during pregnancy and lactation is often elusive (Kosofsky and Hyman 2001; Thompson et al. 2009). The effects of drugs that alter brain development without a physical phenotype or an easily identified neurodevelopmental behavioral phenotype such as seizures or retardation may go undetected and underreported, despite significant impact on brain development and behavior (Kosofsky and Hyman 2001). Furthermore, clinical studies face the extreme complexities of interacting genetic, intrauterine, and postnatal environmental factors that contribute to the drug-induced phenotype. Thus, in order to provide a deeper understanding of the impact of maternal exposure to drugs of abuse on infant and child on later development, and to adopt effective public health strategies, it is critical to stimulate a dialogue between clinical and preclinical investigators. While clinical studies allow to detect basic behavior and some aspects of functional neural activity in humans exposed to drugs of abuse during development, they do not provide information about the specific neuroanatomical, molecular, and cellular consequences that underlie the observed behavioral changes (Thompson et al. 2009). Furthermore, animal studies are essential in controlling for prenatal and postnatal confounding factors and for examining the independent contribution of a certain drug to adverse neurodevelopmental consequences (Fried 2002).

Here, we will summarize and discuss rodent studies examining the long-term behavioral consequences induced by exposure to cannabinoid compounds during pregnancy and/or lactation. First, we will focus on the impact of maternal exposure to cannabinoids on motor behavior, cognitive performance and emotionality in the rat adult offspring. Then, we will examine the role played by maternal cannabinoid exposure in the susceptibility to discriminative and reinforcing effects of drugs of abuse later in life. Last, we will provide experimental evidence showing that maternal cannabis exposure induces long-lasting changes in stress hormones which, in turn, might underlie some of the behavioral changes observed in the exposed offspring. We will consider only studies that used doses of cannabinoid compounds devoid of overt signs of toxicity and/or gross malformations, and that are equivalent to moderate cannabis consumption in humans. For a review of morphological abnormalities and overt signs of toxicity induced by maternal exposure to high doses of cannabinoid compounds, see Abel (1980), El Marroun et al. (2009), Fergusson et al. (2002), Linn et al. (1983).

\section{The endocannabinoid system and the developing brain}

Exhaustive research carried out during the past two decades has demonstrated the existence of the endocannabinoid system in the CNS and also in the periphery, which consists of G-protein-coupled receptors $\left(\mathrm{CB}_{1}\right.$ and $\mathrm{CB}_{2}$ receptors), endogenous ligands (called endocannabinoids), and proteins involved in endocannabinoid synthesis and inactivation (Di Marzo et al. 2005; Di Marzo and Petrocellis 2006; Piomelli 2003). This recently identified system, which is the target of psychoactive cannabis preparations, is thought to have modulatory actions in several neurobiological processes, as has been proposed from the anatomical distribution of cannabinoid receptors in the brain and from the well-known pharmacological effects of cannabinoidrelated compounds (Pacher et al. 2006; Pertwee 2008). 
The endocannabinoid system is present in the CNS during early stages of development, both in laboratory animals and humans, and plays a relevant role in brain organization during pre- and postnatal life (Fernandez-Ruiz et al. 2000; Fride 2004; 2008; Harkany et al. 2007; Romero et al. 1997). Several studies have described the presence of the $\mathrm{CB}_{1}$ cannabinoid receptor (Rodriguez de Fonseca et al. 1993) and its endogenous ligands, anandamide and 2-AG, in the developing brain (Berrendero et al. 1999; Harkany et al. 2007; Mato et al. 2003). $\mathrm{CB}_{1}$ cannabinoid receptors appear to be already functional around gestational days 1114 in rats (Berrendero et al. 1998), and by week 19 of gestation in humans (Mato et al. 2003), since at these stages they are already coupled to signal transduction mechanisms that involve GTP-binding proteins. In both rats and humans, the levels of $\mathrm{CB}_{1}$ receptors at fetal ages are substantially higher than those seen in the adult brain (Berrendero et al. 1999; Mato et al. 2003). This atypical distribution of $\mathrm{CB}_{1}$ receptors has been interpreted, for both species, as indicating a specific role for the endocannabinoid system in several developmental events, such as metabolic support, cell proliferation and migration, axonal elongation and later, synaptogenesis and myelogenesis (Fernandez-Ruiz et al. 2000). The presence of $\mathrm{CB}_{1}$ receptors during brain development has also been associated with neuroprotective effects in the maturation of the CNS and its functions (Fernandez-Ruiz et al. 2000; Fride 2004).

Furthermore, there is a large body of evidence that suggests that exposure to cannabinoids during critical prenatal and early postnatal periods of brain maturation can affect the development of several neurotransmitter systems. In particular, several studies have demonstrated effects of cannabinoids on the maturation of catecholaminergic (Fernandez-Ruiz et al. 2000; Garcia-Gil et al. 1997; Hernandez et al. 2000), serotonergic (Molina-Holgado et al. 1997; Molina-Holgado et al. 1996), GABAergic (Garcia-Gil et al. 1999), glutamatergic (Suarez et al. 2004), and opioidergic systems (Kumar et al. 1990; Vela et al. 1998; Fernandez-Ruiz et al. 2004). All this supports the idea that endocannabinoids have a critical role in brain development, and that targeting the endocannabinoid system by maternal exposure to cannabinoid drugs can lead to enduring developmental changes in the exposed offspring.

\section{Long-term behavioral consequences of maternal cannabis exposure}

\section{Effects on locomotor activity}

The effects of developmental exposure to cannabinoids on locomotor activity later in life are controversial. An increased motor activity in the lactating offspring of mothers receiving THC (10 mg/kg, subcutaneously) during gestational days $6-12$ has been reported; these effects, however, disappeared by postnatal day 21 (Borgen et al. 1973). More recent studies are in agreement with this previous report, demonstrating how rats, exposed to cannabinoids during pregnancy and/or lactation, were characterized by motor hyperactivity at infancy and adolescence, but not at adulthood (Mereu et al. 2003; Navarro et al. 1995). Together, these studies suggest that maternal exposure to cannabinoid drugs might particularly affect the ontogeny of motor behaviors, and are in line with human data showing that children prenatally exposed to cannabis are hyperactive and impulsive (Fried and Smith 2001; Goldschmidt et al. 2004). However, other studies found lower activity in lactating rats perinatally exposed to cannabinoids (Fried 1976) or no effects at all (Brake et al. 1987; Trezza et al. 2008a; Vardaris et al. 1976). Similarly, in adult rats, maternal exposure to cannabinoid compounds has been shown to result in either decreased activity in both males and females (Fride and Mechoulam 1996), increased activity in females only, or no effects (Brake et al. 1987; Trezza et al. 2008a). The different protocols used (i.e., timing of exposure, route of administration, compound used, age of testing, etc.) might account for the different findings of these studies, and make it difficult to draw final conclusions about the long-term effects of maternal cannabis exposure on the locomotor activity of the offspring. Despite the conflicting data obtained in these studies, it is important to note that maternal administration of low doses of cannabinoids seemed to be more effective in inducing temporary changes in locomotor activity in the lactating and young offspring, rather than in adult animals.

\section{Effects on cognitive functions}

Clinical studies have shown that cannabis use during pregnancy induces selective, deleterious effects on executive functions in the offspring both at childhood and adolescence (Day et al. 1994; Fried 2002; Fried and Smith 2001; Fried and Watkinson 2000; Fried et al. 1998). Executive functions comprise capacities such as cognitive flexibility, sustained and focused attention, and working memory. The deficits in executive functions induced by prenatal cannabis exposure seem to be long lasting, since 18-22-year-old young adults exposed to cannabis in utero also showed altered neuronal functioning during visuospatial working memory processing (Smith et al. 2006). However, clinical data on the potential changes induced by cannabis exposure in the long-term expression of cognitive functions later in life are not available yet. Furthermore, despite the consistency in these clinical findings, it cannot be excluded that genetic and environmental variables also contribute to the relationship between 
maternal cannabis use and long-term cognitive deficits in the offspring. Due to these observations, the relationship between antenatal exposure to cannabinoid drugs and longterm cognitive outcomes in the rodent offspring has received a great deal of attention. Prenatal exposure to a moderate dose of the synthetic $\mathrm{CB}_{1}$ cannabinoid receptor agonist WIN55,212-2 induced a disruption of memory retention in 40- and 80-day-old rat offspring tested in the inhibitory avoidance task (Mereu et al. 2003). This cognitive impairment was not due to alterations of nonassociative nature, since the approach latency measured during the acquisition trials of the learning task was unaffected. The memory impairment was associated with alterations in both hippocampal long-term potentiation and glutamate release. The decrease in hippocampal glutamate overflow was suggested to be the cause of long-term potentiation disruption, which could underlie, in turn, the long-lasting impairment of cognitive functions caused by the gestational exposure to the cannabinoid receptor agonist (Mereu et al. 2003). To further support the hypothesis that changes in glutamatergic neurotransmission might be responsible of the cognitive impairment observed in WIN55,212-2-exposed adult offspring, in vivo microdialysis experiments showed that gestational exposure to this cannabinoid receptor agonist induces a consistent reduction of basal and $\mathrm{K}^{+}$-evoked glutamate outflow in the prefrontal cortex of the adult offspring (Antonelli et al. 2004). As for the clinical relevance of these preclinical studies, it is important to estimate, by extrapolation, whether the dose of the synthetic cannabinoid agonist compares with that of THC absorbed by cannabis users. Previous studies have estimated that a dose of $5 \mathrm{mg} / \mathrm{kg}$ of $\mathrm{THC}$ in rats corresponds to a moderate exposure to the drug in humans, correcting for the differences in route of administration and body weight surface area (Garcia-Gil et al. 1997; Garcia-Gil et al. 1999). WIN 55,212-2 has been found to be three to ten times more potent than THC, depending on the administration route and the endpoints considered (Compton et al. 1992; French et al. 1997; Hampson et al. 2000). Based on these considerations, the dose of WIN55,212-2 used in the studies described above $(0.5 \mathrm{mg} / \mathrm{kg}$, subcutaneously $)$ might correspond to a moderate, or even to a low, exposure to cannabis in humans (Mereu et al. 2003). Furthermore, in line with these earlier studies, we have recently demonstrated that the active ingredient of cannabis THC, administered during the perinatal period at a dose $(5 \mathrm{mg} / \mathrm{kg}$, per os, from gestational day 15 to postnatal day 9) that is not associated with gross malformations and/or overt signs of toxicity, induced cognitive impairments in the adult offspring (Campolongo et al. 2007). Perinatal exposure to THC not only induced a long-term memory impairment in the adult offspring, as revealed by the inhibitory avoidance test, but also caused a disruption in short-term olfactory memory, as assessed in the social discrimination test (Campolongo et al. 2007).

Interestingly, the cognitive impairments observed in THC-exposed adult offspring were associated with longlasting alterations in the cortical expression of genes related to glutamatergic neurotransmission, together with a decrease in the cortical extracellular levels of this neurotransmitter (Campolongo et al. 2007). Taken together, these preclinical studies show that maternal cannabis exposure alters cognitive performances in the adult offspring, and strongly suggest that changes in glutamatergic neurotransmission might be responsible for these effects.

\section{Effects on emotionality}

Several preclinical and clinical findings support the hypothesis of an important role of the endocannabinoid system in the modulation of emotional states (Gaetani et al. 2009; Millan 2003; Moreira and Lutz 2008; Viveros et al. 2005; Witkin et al. 2005). First, endocannabinoids are produced throughout the brain and $\mathrm{CB}_{1}$ cannabinoid receptors are particularly expressed in brain areas involved in the modulation of anxious states, such as the cortex, hippocampus, lateral septum, nucleus accumbens, amygdala, and PAG (Ameri 1999; Davies et al. 2002; Hermann et al. 2002; Katona et al. 2001; Schlicker and Kathmann 2001; Tsou et al. 1998). Second, cannabinoids modulate the release of several neurotransmitters implicated in the control of emotionality, such as serotonin, dopamine (Hermann et al. 2002; Katona et al. 2001; Schlicker and Kathmann 2001; Tsou et al. 1998) and the anxiogenic neuropeptides, CCK and CRF (Ameri 1999; Rodriguez de Fonseca et al. 1997). Third, several studies in cannabis users have shown that exposure to hashish and marijuana in humans produces a wide range of subjective emotional effects (Tournier et al. 2003; Wachtel et al. 2002). This may reflect the complex pattern of influence of cannabis on neurotransmitters known to differentially modulate anxiety states. Therefore, it is reasonable to hypothesize that maternal cannabis exposure might induce long-term changes in the emotional reactivity of the offspring. To support this possibility, clinical studies have shown that prenatal exposure to cannabis in the first and third trimesters predicts significantly levels of self-report anxiety and depressive symptoms in 10-year-old children (Goldschmidt et al. 2004; Gray et al. 2005). However, clinical data about the effects of maternal cannabis use on the emotional reactivity of the offspring at adulthood are still missing. Therefore, in addition to epidemiological studies in humans, and considering the intrinsic limitations of this kind of approach, animal models can contribute to clarify if and how exposure to cannabis during pregnancy 
and/or lactation can affect emotional reactivity in the adult offspring.

We demonstrated that perinatal exposure to THC $(5 \mathrm{mg} / \mathrm{kg}$, per os, from gestational day 15 to postnatal day 9) induced long-lasting changes in the emotional reactivity of the offspring (Trezza et al. 2008a). Indeed, compared to vehicle-exposed offspring, THC-exposed rats emitted more ultrasounds when removed from the nest at postnatal day 12 , and spent less time in active social interaction and social play at adolescence (Trezza et al. 2008a). The altered emotional reactivity found in both infant and adolescent offspring perinatally exposed to THC was long lasting, as perinatal THC treatment affected behavior of adult rats in the elevated plus-maze test (Trezza et al. 2008a). Adult rats perinatally treated with THC did indeed spend more time in the closed arms of the maze, exhibited a significantly lower number of head dips and a higher number of stretched-attend postures than vehicle-exposed rats. The number of total entries, however, was not affected by the perinatal treatment, thus suggesting that the locomotor activity of the offspring was not compromised by THC exposure (Trezza et al. 2008a). In line with this finding, a decreased level of social interaction, indicative of an increased emotionality, has been found in the rat offspring exposed to the synthetic cannabinoid receptor agonist CP55,940 from postnatal day 4 to postnatal day 25 (O'Shea et al. 2006). On the other hand, Newsom and Kelly (2008) reported that exposure to THC during early postnatal life $(2 \mathrm{mg} / \mathrm{kg}$, subcutaneously, from gestational day 1 to postnatal day 10) increases the level of social interaction, which could be interpreted as a decrease in emotional reactivity.

Due to the controversies existing among the preclinical studies and to the scarce availability of human data, further studies are needed to clarify the effects induced by maternal cannabinoid exposure on the emotionality of the offspring. One possible explanation for the contrasting data may be related to the different timing of exposure. It is well known how different time windows of exposure to a psychotropic agent can induce even opposite neurofunctional effects (Costa et al. 2004). Moreover, differences in cannabinoid agonist used, tested doses and treatment schedules could also account for the apparent discrepancies (Schneider 2009).

In spite of the controversies, it should be taken into account that, depending on the dose, route of administration and environmental contexts, acute cannabinoid administration may induce both anxiolytic- or anxiogenic-like effects in rodents (Moreira and Lutz 2008; Viveros et al. 2005). It is crucial to consider that all studies, focusing on the offspring emotionality, agree on the evidence that cannabinoid exposure during critical developmental periods may induce, even if in an opposite way, enduring changes in the emotional reactivity of the adult offspring.
Effects on drug sensitivity in later life

Cannabinoid and opioid neurotransmission are known to closely interact in many physiological and pathological functions, such as pain management, appetite regulation, social interactions, and drug addiction (Cota et al. 2006; Fattore et al. 2005; Maldonado and Valverde 2003; Solinas and Goldberg 2005; Spano et al. 2009; Trezza and Vanderschuren 2008a, b). Therefore, the possibility that maternal cannabis consumption might affect sensitivity towards the reinforcing properties of opioids in adulthood has been addressed in several preclinical studies. Vela and coworkers reported that adult female, but not male, rats exposed to THC during pregnancy and lactation showed increased rate of acquisition of morphine self-administration under a fixed-ratio schedule of reinforcement at adulthood (Vela et al. 1998). Compared to vehicle-exposed rats, THCexposed males exhibited a lower density of $\mu$-opioid receptors in the caudate-putamen area as well as in the amygdala, whereas THC-exposed females exhibited higher density of these receptors in the prefrontal cortex, the hippocampus, the amygdala, the ventral tegmental area, and the periaqueductal gray matter (Vela et al. 1998). These results support the notion that perinatal THC exposure alters the susceptibility to the reinforcing effects of morphine in adult female offspring, in parallel with changes in $\mu$-opioid receptor binding in several brain regions. However, in a follow-up study, the same regimen of THC administration had no effects on both food and morphine self-administration under a progressive-ratio schedule of reinforcement in adulthood (Gonzalez et al. 2003). Differences in the response requirements between fixed- and progressive-ratio schedules of reinforcement might explain these apparently conflicting observations. Indeed, the number of lever presses required to obtain a drug injection is constant in fixed-ratio schedules, while it is increased with successive injections in progressive-ratio schedules. Thus, a fixed-ratio schedule reveals if a drug is reinforcing or not, but the reinforcing efficacy of this drug needs to be tested in a progressive-ratio schedule. Therefore, we might conclude that morphine was particularly preferred by adult females that had been perinatally exposed to THC (Vela et al. 1998), but this vulnerability to morphine disappeared if animals had to work harder to get the drug (Gonzalez et al. 2003). More recently, Spano and colleagues found that adult rats prenatally exposed to THC did not show enhanced heroin intake under normal conditions (Spano et al. 2007). However, enkephalin expression in brain regions implicated in reward and stress, such as the nucleus accumbens and amygdala, was altered following prenatal THC exposure (Spano et al. 2007). Furthermore, THC-exposed adult offspring showed enhanced heroin-seeking during mild stress and extinction 
(Spano et al. 2007). These findings suggest an altered behavioral response to stress which intensifies the motivation for drug use in THC-exposed subjects, rather than just altered sensitivity to the reinforcing effects of the drug.

The possibility that in utero THC exposure induces sensitization to opiates has also been addressed by evaluating morphine- (Rubio et al. 1998; Rubio et al. 1995) or heroin(Singh et al. 2006) induced place conditioning in the adult rat offspring. In both cases, the results showed that THCexposed adult offspring exhibited an enhanced sensitivity to the rewarding effects of opioid drugs.

Concerning the effects of maternal cannabis exposure on adult sensitivity to other drugs of abuse, Economidou and coworkers reported no effects of perinatal THC exposure on ethanol self-administration in the adult offspring (Economidou et al. 2007). However, the effects of maternal cannabis exposure on adult sensitivity to drugs like psychostimulants, hallucinogens, and also cannabinoids are still unknown. Therefore, more studies are needed in order to determine whether maternal cannabis use has a direct casual influence on other illicit drug use. Furthermore, it is also important to note that preclinical studies about the relationship between maternal cannabis exposure and drug abuse later in life do not exclude the contribution of other factors such as environment and social issues that could influence the direct neurobiological effects of early THC exposure to either enhance or attenuate the progression to adult drug abuse. Caution is therefore advised when extending the results of these studies to human drug abuse.

\section{Other behavioral effects}

Consistent data are available about the effects of maternal cannabis exposure on reflex reactivity to external stimuli in the offspring. Oral administration of THC to pregnant rats did not change the auditory startle response of the offspring at adulthood (Hutchings et al. 1991). More recent studies confirmed this early finding by showing that prenatal cannabinoid exposure did not affect startle magnitude and sensorimotor gating in the offspring tested at 40,60 , and 80 days of age (Bortolato et al. 2006). Together, these studies suggest that prenatal exposure to cannabis derivatives does not affect reflex reactivity to environmental stimuli in the offspring.

Perinatal exposure to cannabinoid compounds increased the frequency and the time spent by adult rats in spontaneous and water-induced grooming behavior measured in a novel environment (Navarro et al. 1995): this indicates that maternal cannabis exposure induces stereotyped behaviors that might be the consequence of an altered response to novelty (Navarro et al. 1995).

Early studies showed that perinatal cannabinoid exposure altered sexual behavior of adult male mice (Dalterio and Bartke 1979; Dalterio et al. 1984a; b) and rats (Fried and Charlebois 1979) that showed a longer latency to mount a receptive female. Subsequent studies confirmed these early findings, by showing that maternal exposure to cannabis extracts altered the pattern of approach to sexually receptive females in a sexual orientation test in the male rat offspring (Navarro et al. 1996).

A complete overview of the long-term behavioral effects of maternal cannabinoid exposure in rats is given in Table 1 .

\section{Long-term neuroendocrine effects induced by maternal cannabis exposure}

The endocannabinoid system is known to modulate the activity of the hypothalamus-pituitary-adrenal (HPA) axis (Cota 2008; Hill and McEwen 2009b; Rodriguez de Fonseca et al. 1991; Weidenfeld et al. 1994). Interestingly, the effects of endocannabinoids on the HPA axis are consistent with their neuromodulatory action on brain neurotransmitter systems. For instance, endocannabinoids have been found to mediate the nongenomic glucocorticoid-induced inhibition of glutamate release within the paraventricular nucleus of the hypothalamus (Di et al. 2003), or to mediate glucocorticoidinduced inhibition of spontaneous neuronal activity and sensory responsiveness of medullary neurons (Coddington et al. 2007). These data, together with our recent findings showing that endocannabinoids mediate glucocorticoidinduced enhancement of emotional memory processing in the amygdala (Campolongo et al. 2009a), led to the hypothesis that endocannabinoids might play a crucial role in the fast nongenomic neuronal actions of glucocorticoids (Hill and McEwen 2009a).

Glucocorticoids, in turn, are well-known epigenetic factors able to affect brain development (McEwen 1992), and it has been suggested that activation of the HPA axis might underlie the neurobehavioral changes observed after perinatal exposure to either drugs of abuse or stress (McEwen 1987). Therefore, it is possible that some of the neurodevelopmental effects induced by maternal cannabis exposure might be due to changes in the epigenetic role of stress hormones on brain development. Data from animal studies support this possibility. It has been reported that adult female rats exposed to THC during pregnancy and lactation exhibited higher levels of both corticotrophin releasing factor (CRF-41) in the medial basal hypothalamus and plasma corticosterone, whereas THC-exposed males showed lower levels of both endocrine parameters (Navarro et al. 1995; Rubio et al. 1995). In a subsequent study, the same group showed that perinatal exposure to doses of the synthetic cannabinoid agonist HU-210 equipotent to human cannabis consumption resulted in a dose-dependent decrease in plasma corticosterone levels in the adult male 
Table 1 Long-term behavioral effects of maternal cannabinoid exposure in rats

\begin{tabular}{llll}
\hline Drug & $\begin{array}{l}\text { Treatment } \\
\text { period }\end{array}$ & Behavioral effects & Refs \\
\hline
\end{tabular}

Locomotor activity

THC $10 \mathrm{mg} / \mathrm{kg}$ (s.c.)

THC $5 \mathrm{mg} / \mathrm{kg}$ (p.o.)

THC $5 \mathrm{mg} / \mathrm{kg}$ (p.o.)

THC $2 \mathrm{mg} / \mathrm{kg}$ (p.o.)

THC $15-50 \mathrm{mg} / \mathrm{kg}$ (р.o.)

THC $3.3 \mathrm{mg} / \mathrm{kg}$ approximately (p.i.)

WIN55,212-2 $0.5 \mathrm{mg} / \mathrm{kg}$ (s.c.)

Cognitive functions

WIN55,212-2 $0.5 \mathrm{mg} / \mathrm{kg}$ (s.c.)

THC $5 \mathrm{mg} / \mathrm{kg}$ (p.o.)

Emotionality

THC $5 \mathrm{mg} / \mathrm{kg}$ (p.o.)

CP55,940 (increasing doses: $0.15,0.20$, $0.30 \mathrm{mg} / \mathrm{kg}$ for 7 days at each dose, s.c.) THC $2 \mathrm{mg} / \mathrm{kg}$ (s.c.)

GD 6-GD 12

GD 5-PND 24

GD 15-PND 9

GD 3-GD22

GD 8-GD 22

GD 1-GD 19

GD 5-GD 20

GD 5-GD 20

GD 15-PND 9

Drug sensitivity later in life

THC $5 \mathrm{mg} / \mathrm{kg}$ (p.o.)

THC $5 \mathrm{mg} / \mathrm{kg}$ (p.o.)

THC $0.15 \mathrm{mg} / \mathrm{kg}$ (i.v.)

THC $1-5 \mathrm{mg} / \mathrm{kg}$ (p.o.)

THC $5 \mathrm{mg} / \mathrm{kg}$ (p.o.)

THC $5 \mathrm{mg} / \mathrm{kg}$ (p.o.)

Other behavioral effects

THC $15-30 \mathrm{mg} / \mathrm{kg}$ (p.o.)

WIN55,212-2 $0.5-1 \mathrm{mg} / \mathrm{kg}$ (s.c.)

THC $5 \mathrm{mg} / \mathrm{kg}$ (p.o.)

Hashish extract $20 \mathrm{mg} / \mathrm{kg}$ (p.o.)
PND 4-PND 25

GD 5-PND 24

GD 15-PND 9 Increased rate of separation-induced ultrasonic vocalizations at PND 12; reduced social interaction and play behavior at PND 35; increased anxietyrelated behavior in the elevated plus-maze test at PND 80 (males)

Reduced social interaction at PND 60 (males)

GD 1-PND 10 Increased social interaction at PND 90 (males)

GD 5-PND 24 Increased rate of acquisition of morphine self-administration under a fixed-ratio schedule in adult females (no effects in males)

GD 5-PND 24 No effect on food or morphine self-administration in a progressive-ratio schedule in both adult males and females

GD 5-PND 2 No differences in heroine self-administration under normal conditions; however, increased heroinseeking during mild stress and extinction (PND 62, males)

Enhanced sensitivity towards the rewarding effects of morphine in a conditioned place preference paradigm both in adult males and females

GD 5-PND 24 Enhanced sensitivity towards the rewarding effects of morphine in a conditioned place preference paradigm both in adult males and females

GD 15-PND 9 No effects on ethanol self-administration in adult males

GD 2-GD 22 No effects on auditory startle at PND 57-60 in both males and females

GD 5-GD $20 \quad$ No effects on startle magnitude and sensorimotor gating at PND 40,60 and 80 (males)

GD 5-PND 24 Increase in the frequency and time spent grooming in both adult males and females

GD 5-PND 24 Altered pattern of approach of adult males toward sexually receptive females
Borgen et al. 1973

Navarro et al. 1995

Trezza et al. 2008a

Vardaris et al. 1976

Brake et al. 1987

Fried 1976

Mereu et al. 2003

Mereu et al. 2003

Campolongo et al. 2007

Trezza et al. 2008a

O'Shea et al. 2006

Newsom and Kelly 2008

Vela et al. 1998

Gonzalez et al. 2003

Spano et al. 2007

Rubio et al. 1998

Rubio et al. 1995

Economidou et al. 2007

Hutchings et al. 1991

Bortolato et al. 2006

Navarro et al. 1995

Navarro et al. 1996

$G D$ gestational day, $P N D$ postnatal day, p.o. per os, s.c. subcutaneously, i.v. intravenously, p.i. per inhalation 
offspring, and in clear alterations in the responsiveness of the HPA axis to an acute stimulatory challenge with HU210 (del Arco et al. 2000). The authors suggest that these endocrine alterations might reflect compensatory mechanisms for the presence of higher levels of corticosterone during fetal development following a HU-210-induced increase in corticosterone in maternal blood (Rodriguez de Fonseca et al. 1995; Ward and Weisz 1984). Interestingly, offspring perinatally exposed to high levels of the synthetic cannabinoid agonist showed a decreased responsiveness of the HPA axis to stressors at adult ages, whereas offspring perinatally exposed to low levels of the same cannabinoid compound showed a sensitization of the HPA axis (del Arco et al. 2000). These data point out that maternal exposure to even low doses of cannabinoid compounds induces longlasting alterations in the functionality of the HPA axis that, in turn, might result in an impairment in the behavioral and neuroendocrine response to stress in the adult offspring. To support this interpretation, it has been shown that neonatal administration of THC alters the neurochemical response to stress in adult rats (Mokler et al. 1987). Further research, however, is needed to establish the precise role of stress hormones in the neurobehavioral consequences induced by maternal cannabis exposure.

\section{Conclusions}

The effects of maternal drug exposure on brain development and behavior later in life are complex, and are modulated by several factors like timing, dose, and route of drug exposure. Investigating these effects in human studies is difficult, due to frequent simultaneous exposure to multiple drugs, difficulties in documenting use patterns, influence of social and genetic factors, and practical problems in conducting long-term prospective longitudinal studies. Therefore, preclinical studies provide a unique opportunity to identify the long-lasting behavioral abnormalities induced by maternal drug exposure, and the specific neuroanatomical, molecular, and cellular changes that underlie these behavioral effects (Thompson et al. 2009).

The preclinical studies reviewed in this article outlined that cannabinoid drugs are neuroteratogens able to induce long-lasting behavioral abnormalities in the exposed offspring. In particular, administration of even low doses of cannabinoid compounds during development results in atypical development of locomotor activity, cognitive impairments, altered emotional behavior and enhanced drug sensitivity later in life. Although most longitudinal prospective studies (Fried 2002; Fried and Smith 2001; Goldschmidt et al. 2004; Gray et al. 2005; Smith et al. 2006) about the long-term effects of maternal cannabis exposure in humans are still in progress, some of the preclinical findings reviewed in this article are in line with clinical studies reporting hyperactivity, cognitive impairments, and altered emotionality in humans exposed to cannabis during pregnancy and/or lactation (Fried and Smith 2001; Fried et al. 1992; Goldschmidt et al. 2000; 2004; Gray et al. 2005; Smith et al. 2006). This parallelism further support the utility of animal studies in getting information about the long-term neurobehavioral outcomes of maternal cannabis use that is relevant to the human exposure. Conversely, although animal models allow to control for several confounding factors associated with human studies, they do not take into account environmental and social factors that could influence the long-term neurobehavioral effects of maternal cannabis exposure. This issue is particularly important when assessing the effects of early cannabis exposure on drug sensitivity later in life. Therefore, it is clear that only a dialogue between clinical and preclinical investigators will allow to determine the precise risk of maternal cannabis use, the neurobiological mechanisms underlying the altered behavioral phenotype observed in cannabis-exposed subjects, and the interaction between drug exposure and other factors that influence fetal brain development, like maternal stress, social, genetic, and environmental factors.

Open Access This article is distributed under the terms of the Creative Commons Attribution Noncommercial License which permits any noncommercial use, distribution, and reproduction in any medium, provided the original author(s) and source are credited.

\section{References}

Abel EL (1980) Prenatal exposure to cannabis: a critical review of effects on growth, development, and behavior. Behav Neural Biol 29:137-156

Ameri A (1999) The effects of cannabinoids on the brain. Prog Neurobiol 58:315-348

Antonelli T, Tanganelli S, Tomasini MC, Finetti S, Trabace L, Steardo L, Sabino V, Carratu MR, Cuomo V, Ferraro L (2004) Long-term effects on cortical glutamate release induced by prenatal exposure to the cannabinoid receptor agonist $(R)-(+)-[2,3$-dihydro-5-methyl3-(4-morpholinyl-methyl)pyrrolo[1, 2, 3-de]-1, 4-benzoxazin-6-yl]1-naphthalenylmethanone: an in vivo microdialysis study in the awake rat. Neuroscience 124:367-375

Berrendero F, Garcia-Gil L, Hernandez ML, Romero J, Cebeira M, de Miguel R, Ramos JA, Fernandez-Ruiz JJ (1998) Localization of mRNA expression and activation of signal transduction mechanisms for cannabinoid receptor in rat brain during fetal development. Development 125:3179-3188

Berrendero F, Sepe N, Ramos JA, Di Marzo V, Fernandez-Ruiz JJ (1999) Analysis of cannabinoid receptor binding and mRNA expression and endogenous cannabinoid contents in the developing rat brain during late gestation and early postnatal period. Synapse 33:181-191

Borgen LA, Lott GC, Davis WM (1973) Cannabis-induced hypothermia: a dose-effect comparison of crude marihuana extract and synthetic 
9-tetrahydrocannabinol in male and female rats. Res Commun Chem Pathol Pharmacol 5:621-626

Bortolato M, Frau R, Orru M, Casti A, Aru GN, Fa M, Manunta M, Usai A, Mereu G, Gessa GL (2006) Prenatal exposure to a cannabinoid receptor agonist does not affect sensorimotor gating in rats. Eur J Pharmacol 531:166-170

Brake SC, Hutchings DE, Morgan B, Lasalle E, Shi T (1987) Delta-9tetrahydrocannabinol during pregnancy in the rat: II. Effects on ontogeny of locomotor activity and nipple attachment in the offspring. Neurotoxicol Teratol 9:45-49

Campolongo P, Trezza V, Cassano T, Gaetani S, Morgese MG, Ubaldi M, Soverchia L, Antonelli T, Ferraro L, Massi M, Ciccocioppo R, Cuomo V (2007) Perinatal exposure to delta-9-tetrahydrocannabinol causes enduring cognitive deficits associated with alteration of cortical gene expression and neurotransmission in rats. Addict Biol $12: 485-495$

Campolongo P, Roozendaal B, Trezza V, Hauer D, Schelling G, McGaugh JL, Cuomo V (2009a) Endocannabinoids in the rat basolateral amygdala enhance memory consolidation and enable glucocorticoid modulation of memory. Proc Natl Acad Sci USA 106:4888-4893

Campolongo P, Trezza V, Palmery M, Trabace L, Cuomo V (2009b) Developmental exposure to cannabinoids causes subtle and enduring neurofunctional alterations. Int Rev Neurobiol 85:117-133

Coddington E, Lewis C, Rose JD, Moore FL (2007) Endocannabinoids mediate the effects of acute stress and corticosterone on sex behavior. Endocrinology 148:493-500

Compton DR, Gold LH, Ward SJ, Balster RL, Martin BR (1992) Aminoalkylindole analogs: cannabimimetic activity of a class of compounds structurally distinct from delta 9-tetrahydrocannabinol. J Pharmacol Exp Ther 263:1118-1126

Costa LG, Steardo L, Cuomo V (2004) Structural effects and neurofunctional sequelae of developmental exposure to psychotherapeutic drugs: experimental and clinical aspects. Pharmacol Rev 56:103-147

Cota D (2008) The role of the endocannabinoid system in the regulation of hypothalamic-pituitary-adrenal axis activity. J Neuroendocrinol 20(Suppl 1):35-38

Cota D, Tschop MH, Horvath TL, Levine AS (2006) Cannabinoids, opioids and eating behavior: the molecular face of hedonism? Brain Res Brain Res Rev 51:85-107

Coyle I, Wayner MJ, Singer G (1976) Behavioral teratogenesis: a critical evaluation. Pharmacol Biochem Behav 4:191-200

Dalterio S, Bartke A (1979) Perinatal exposure to cannabinoids alters male reproductive function in mice. Science 205:1420-1422

Dalterio S, Steger R, Mayfield D, Bartke A (1984a) Early cannabinoid exposure influences neuroendocrine and reproductive functions in male mice: I. Prenatal exposure. Pharmacol Biochem Behav 20:107-113

Dalterio S, Steger R, Mayfield D, Bartke A (1984b) Early cannabinoid exposure influences neuroendocrine and reproductive functions in mice: II. Postnatal effects. Pharmacol Biochem Behav 20: $115-123$

Davies SN, Pertwee RG, Riedel G (2002) Functions of cannabinoid receptors in the hippocampus. Neuropharmacology 42:993-1007

Day NL, Richardson GA, Goldschmidt L, Robles N, Taylor PM, Stoffer DS, Cornelius MD, Geva D (1994) Effect of prenatal marijuana exposure on the cognitive development of offspring at age three. Neurotoxicol Teratol 16:169-175

del Arco I, Munoz R, Rodriguez De Fonseca F, Escudero L, MartinCalderon JL, Navarro M, Villanua MA (2000) Maternal exposure to the synthetic cannabinoid HU-210: effects on the endocrine and immune systems of the adult male offspring. Neuroimmunomodulation 7:16-26

Di Marzo V, Petrocellis LD (2006) Plant, synthetic, and endogenous cannabinoids in medicine. Annu Rev Med 57:553-574
Di Marzo V, De Petrocellis L, Bisogno T (2005) The biosynthesis, fate and pharmacological properties of endocannabinoids. Handb Exp Pharmacol 147-185

Di S, Malcher-Lopes R, Halmos KC, Tasker JG (2003) Nongenomic glucocorticoid inhibition via endocannabinoid release in the hypothalamus: a fast feedback mechanism. J Neurosci 23: $4850-4857$

Economidou D, Mattioli L, Ubaldi M, Lourdusamy A, Soverchia L, Hardiman G, Campolongo P, Cuomo V, Ciccocioppo R (2007) Role of cannabinoidergic mechanisms in ethanol selfadministration and ethanol seeking in rat adult offspring following perinatal exposure to Delta9-tetrahydrocannabinol. Toxicol Appl Pharmacol 223:73-85

El Marroun H, Tiemeier H, Steegers EA, Jaddoe VW, Hofman A, Verhulst FC, van den Brink W, Huizink AC (2009) Intrauterine cannabis exposure affects fetal growth trajectories: the generation R Study. J Am Acad Child Adolesc Psychiatry

Fattore L, Deiana S, Spano SM, Cossu G, Fadda P, Scherma M, Fratta W (2005) Endocannabinoid system and opioid addiction: behavioural aspects. Pharmacol Biochem Behav 81:343-359

Fergusson DM, Horwood LJ, Northstone K (2002) Maternal use of cannabis and pregnancy outcome. Bjog 109:21-27

Fernandez-Ruiz J, Berrendero F, Hernandez ML, Ramos JA (2000) The endogenous cannabinoid system and brain development. Trends Neurosci 23:14-20

Fernandez-Ruiz J, Gomez M, Hernandez M, de Miguel R, Ramos JA (2004) Cannabinoids and gene expression during brain development. Neurotox Res 6:389-401

French ED, Dillon K, Wu X (1997) Cannabinoids excite dopamine neurons in the ventral tegmentum and substantia nigra. NeuroReport 8:649-652

Fride E (2004) The endocannabinoid-CB(1) receptor system in preand postnatal life. Eur J Pharmacol 500:289-297

Fride E (2008) Multiple roles for the endocannabinoid system during the earliest stages of life: pre- and postnatal development. J Neuroendocrinol 20(Suppl 1):75-81

Fride E, Mechoulam R (1996) Developmental aspects of anandamide: ontogeny of response and prenatal exposure. Psychoneuroendocrinology 21:157-172

Fried PA (1976) Short and long-term effects of pre-natal cannabis inhalation upon rat offspring. Psychopharmacology (Berl) 50:285-291

Fried PA (2002) Conceptual issues in behavioral teratology and their application in determining long-term sequelae of prenatal marihuana exposure. J Child Psychol Psychiatry 43:81-102

Fried PA, Charlebois AT (1979) Cannabis administered during pregnancy: First - and second - generation effects in rats. Physiol Psychol 307-310

Fried PA, Smith AM (2001) A literature review of the consequences of prenatal marihuana exposure. An emerging theme of a deficiency in aspects of executive function. Neurotoxicol Teratol 23:1-11

Fried PA, Watkinson B (2000) Visuoperceptual functioning differs in 9- to 12-year olds prenatally exposed to cigarettes and marihuana. Neurotoxicol Teratol 22:11-20

Fried PA, Watkinson B, Gray R (1992) A follow-up study of attentional behavior in 6-year-old children exposed prenatally to marihuana, cigarettes, and alcohol. Neurotoxicol Teratol 14:299-311

Fried PA, Watkinson B, Gray R (1998) Differential effects on cognitive functioning in 9- to 12-year olds prenatally exposed to cigarettes and marihuana. Neurotoxicol Teratol 20:293-306

Gaetani S, Dipasquale P, Romano A, Righetti L, Cassano T, Piomelli D, Cuomo V (2009) The endocannabinoid system as a target for novel anxiolytic and antidepressant drugs. Int Rev Neurobiol 85:57-72

Garcia-Gil L, De Miguel R, Munoz RM, Cebeira M, Villanua MA, Ramos JA, Fernandez-Ruiz JJ (1997) Perinatal delta(9)-tetrahydrocannabinol exposure alters the responsiveness of hypothalam- 
ic dopaminergic neurons to dopamine-acting drugs in adult rats. Neurotoxicol Teratol 19:477-487

Garcia-Gil L, de Miguel R, Romero J, Perez A, Ramos JA, FernandezRuiz JJ (1999) Perinatal delta9-tetrahydrocannabinol exposure augmented the magnitude of motor inhibition caused by GABA (B), but not GABA(A), receptor agonists in adult rats. Neurotoxicol Teratol 21:277-283

Goldschmidt L, Day NL, Richardson GA (2000) Effects of prenatal marijuana exposure on child behavior problems at age 10 . Neurotoxicol Teratol 22:325-336

Goldschmidt L, Richardson GA, Cornelius MD, Day NL (2004) Prenatal marijuana and alcohol exposure and academic achievement at age 10. Neurotoxicol Teratol 26:521-532

Gonzalez B, de Miguel R, Martin S, Perez-Rosado A, Romero J, Garcia-Lecumberri C, Fernandez-Ruiz J, Ramos JA, Ambrosio E (2003) Effects of perinatal exposure to delta 9-tetrahydrocannabinol on operant morphine-reinforced behavior. Pharmacol Biochem Behav 75:577-584

Gray KA, Day NL, Leech S, Richardson GA (2005) Prenatal marijuana exposure: effect on child depressive symptoms at ten years of age. Neurotoxicol Teratol 27:439-448

Hampson RE, Mu J, Deadwyler SA (2000) Cannabinoid and kappa opioid receptors reduce potassium $\mathrm{K}$ current via activation of $\mathrm{G}$ (s) proteins in cultured hippocampal neurons. J Neurophysiol 84:2356-2364

Harkany T, Guzman M, Galve-Roperh I, Berghuis P, Devi LA, Mackie K (2007) The emerging functions of endocannabinoid signaling during CNS development. Trends Pharmacol Sci 28:83-92

Hermann H, Marsicano G, Lutz B (2002) Coexpression of the cannabinoid receptor type 1 with dopamine and serotonin receptors in distinct neuronal subpopulations of the adult mouse forebrain. Neuroscience 109:451-460

Hernandez M, Berrendero F, Suarez I, Garcia-Gil L, Cebeira M, Mackie K, Ramos JA, Fernandez-Ruiz J (2000) Cannabinoid CB (1) receptors colocalize with tyrosine hydroxylase in cultured fetal mesencephalic neurons and their activation increases the levels of this enzyme. Brain Res 857:56-65

Hill MN, McEwen BS (2009a) Endocannabinoids: the silent partner of glucocorticoids in the synapse. Proc Natl Acad Sci USA 106:4579-4580

Hill MN, McEwen BS (2009b) Involvement of the endocannabinoid system in the neurobehavioural effects of stress and glucocorticoids. Prog Neuropsychopharmacol Biol Psychiatry

Huizink AC, Mulder EJ (2006) Maternal smoking, drinking or cannabis use during pregnancy and neurobehavioral and cognitive functioning in human offspring. Neurosci Biobehav Rev 30:24-41

Hutchings DE, Martin BR, Gamagaris Z, Miller N, Fico T (1989) Plasma concentrations of delta-9-tetrahydrocannabinol in dams and fetuses following acute or multiple prenatal dosing in rats. Life Sci 44:697-701

Hutchings DE, Brake SC, Banks AN, Nero TJ, Dick LS, Zmitrovich AC (1991) Prenatal delta-9-tetrahydrocannabinol in the rat: effects on auditory startle in adulthood. Neurotoxicol Teratol $13: 413-416$

Jakubovic A, Hattori T, McGeer PL (1977) Radiactivity in suckled rats after giving $14 \mathrm{C}$-tetrahydrocannabinol to the mother. Eur J Pharmacol 22:221-223

Jones KL, Smith DW (1973) Recognition of the fetal alcohol syndrome in early infancy. Lancet 2:999-1001

Katona I, Rancz EA, Acsady L, Ledent C, Mackie K, Hajos N, Freund TF (2001) Distribution of CB1 cannabinoid receptors in the amygdala and their role in the control of GABAergic transmission. J Neurosci 21:9506-9518

Kosofsky BE, Hyman SE (2001) No time for complacency: the fetal brain on drugs. J Comp Neurol 435:259-262
Kumar AM, Haney M, Becker T, Thompson ML, Kream RM, Miczek K (1990) Effect of early exposure to delta-9-tetrahydrocannabinol on the levels of opioid peptides, gonadotropin-releasing hormone and substance $\mathrm{P}$ in the adult male rat brain. Brain Res 525:78-83

Linn S, Schoenbaum SC, Monson RR, Rosner R, Stubblefield PC, Ryan KJ (1983) The association of marijuana use with outcome of pregnancy. Am J Public Health 73:1161-1164

Maldonado R, Valverde O (2003) Participation of the opioid system in cannabinoid-induced antinociception and emotional-like responses. Eur Neuropsychopharmacol 13:401-410

Mato S, Del Olmo E, Pazos A (2003) Ontogenetic development of cannabinoid receptor expression and signal transduction functionality in the human brain. Eur J Neurosci 17:1747-1754

McEwen BS (1987) Steroid hormones and brain development: some guidelines for understanding actions of pseudohormones and other toxic agents. Environ Health Perspect 74:177-184

McEwen BS (1992) Steroid hormones: effect on brain development and function. Horm Res 37(Suppl 3):1-10

Mereu G, Fa M, Ferraro L, Cagiano R, Antonelli T, Tattoli M, Ghiglieri V, Tanganelli S, Gessa GL, Cuomo V (2003) Prenatal exposure to a cannabinoid agonist produces memory deficits linked to dysfunction in hippocampal long-term potentiation and glutamate release. Proc Natl Acad Sci USA 100:4915-4920

Millan MJ (2003) The neurobiology and control of anxious states. Prog Neurobiol 70:83-244

Mokler DJ, Robinson SE, Johnson JH, Hong JS, Rosecrans JA (1987) Neonatal administration of delta-9-tetrahydrocannabinol (THC) alters the neurochemical response to stress in the adult Fischer344 rat. Neurotoxicol Teratol 9:321-327

Molina-Holgado F, Amaro A, Gonzalez MI, Alvarez FJ, Leret ML (1996) Effect of maternal delta 9-tetrahydrocannabinol on developing serotonergic system. Eur J Pharmacol 316:39-42

Molina-Holgado F, Alvarez FJ, Gonzalez I, Antonio MT, Leret ML (1997) Maternal exposure to delta 9-tetrahydrocannabinol (delta 9-THC) alters indolamine levels and turnover in adult male and female rat brain regions. Brain Res Bull 43:173-178

Moreira FA, Lutz B (2008) The endocannabinoid system: emotion, learning and addiction. Addict Biol 13:196-212

Navarro M, Rubio P, de Fonseca FR (1995) Behavioural consequences of maternal exposure to natural cannabinoids in rats. Psychopharmacology (Berl) 122:1-14

Navarro M, de Miguel R, Rodriguez de Fonseca F, Ramos JA, Fernandez-Ruiz JJ (1996) Perinatal cannabinoid exposure modifies the sociosexual approach behavior and the mesolimbic dopaminergic activity of adult male rats. Behav Brain Res 75:91-98

Newsom RJ, Kelly SJ (2008) Perinatal delta-9-tetrahydrocannabinol exposure disrupts social and open field behavior in adult male rats. Neurotoxicol Teratol 30:213-219

O'Shea M, McGregor IS, Mallet PE (2006) Repeated cannabinoid exposure during perinatal, adolescent or early adult ages produces similar long-lasting deficits in object recognition and reduced social interaction in rats. J Psychopharmacol

Pacher P, Batkai S, Kunos G (2006) The endocannabinoid system as an emerging target of pharmacotherapy. Pharmacol Rev 58:389-462

Pertwee RG (2008) The diverse CB1 and CB2 receptor pharmacology of three plant cannabinoids: delta9-tetrahydrocannabinol, cannabidiol and delta9-tetrahydrocannabivarin. $\mathrm{Br} \mathrm{J}$ Pharmacol 153:199-215

Piomelli D (2003) The molecular logic of endocannabinoid signalling. Nat Rev Neurosci 4:873-884

Rodriguez de Fonseca F, Fernandez-Ruiz JJ, Murphy L, Eldridge JC, Steger RW, Bartke A (1991) Effects of delta-9-tetrahydrocannabinol exposure on adrenal medullary function: evidence of an acute effect and development of tolerance in chronic treatments. Pharmacol Biochem Behav 40:593-598 
Rodriguez de Fonseca F, Ramos JA, Bonnin A, Fernandez-Ruiz JJ (1993) Presence of cannabinoid binding sites in the brain from early postnatal ages. NeuroReport 4:135-138

Rodriguez de Fonseca FR, Villanua MA, Munoz RM, San-Martin-Clark O, Navarro M (1995) Differential effects of chronic treatment with either dopamine D1 or D2 receptor agonists on the acute neuroendocrine actions of the highly potent synthetic cannabinoid HU-210 in male rats. Neuroendocrinology 61:714-721

Rodriguez de Fonseca F, Carrera MR, Navarro M, Koob GF, Weiss F (1997) Activation of corticotropin-releasing factor in the limbic system during cannabinoid withdrawal. Science 276: 2050-2054

Romero J, Garcia-Palomero E, Berrendero F, Garcia-Gil L, Hernandez ML, Ramos JA, Fernandez-Ruiz JJ (1997) Atypical location of cannabinoid receptors in white matter areas during rat brain development. Synapse 26:317-323

Rubio P, Rodriguez de Fonseca F, Munoz RM, Ariznavarreta C, Martin-Calderon JL, Navarro M (1995) Long-term behavioral effects of perinatal exposure to delta 9-tetrahydrocannabinol in rats: possible role of pituitary-adrenal axis. Life Sci $56: 2169-2176$

Rubio P, Rodriguez de Fonseca F, Martin-Calderon JL, Del Arco I, Bartolome S, Villanua MA, Navarro M (1998) Maternal exposure to low doses of delta9-tetrahydrocannabinol facilitates morphineinduced place conditioning in adult male offspring. Pharmacol Biochem Behav 61:229-238

Schlicker E, Kathmann M (2001) Modulation of transmitter release via presynaptic cannabinoid receptors. Trends Pharmacol Sci 22:565-572

Schneider M (2009) Cannabis use in pregnancy and early life and its consequences: animal models. Eur Arch Psychiatry Clin Neurosci 259:383-393

Singh ME, McGregor IS, Mallet PE (2006) Perinatal exposure to delta (9)-tetrahydrocannabinol alters heroin-induced place conditioning and fos-immunoreactivity. Neuropsychopharmacology 31:58-69

Smith AM, Fried PA, Hogan MJ, Cameron I (2006) Effects of prenatal marijuana on visuospatial working memory: an fMRI study in young adults. Neurotoxicol Teratol 28:286-295

Solinas M, Goldberg SR (2005) Motivational effects of cannabinoids and opioids on food reinforcement depend on simultaneous activation of cannabinoid and opioid systems. Neuropsychopharmacology 30:2035-2045

Spano MS, Ellgren M, Wang X, Hurd YL (2007) Prenatal cannabis exposure increases heroin seeking with allostatic changes in limbic enkephalin systems in adulthood. Biol Psychiatry 61: $554-563$

Spano MS, Fadda P, Fratta W, Fattore L (2009) Cannabinoid-opioid interactions in drug discrimination and self-administration: effect of maternal, postnatal, adolescent and adult exposure to the drugs. Curr Drug Targets

Suarez I, Bodega G, Fernandez-Ruiz J, Ramos JA, Rubio M, Fernandez B (2004) Down-regulation of the AMPA glutamate receptor subunits GluR1 and GluR2/3 in the rat cerebellum following pre- and perinatal delta9-tetrahydrocannabinol exposure. Cerebellum 3:66-74

Thompson BL, Levitt P, Stanwood GD (2009) Prenatal exposure to drugs: effects on brain development and implications for policy and education. Nat Rev Neurosci 10:303-312

Tournier M, Sorbara F, Gindre C, Swendsen JD, Verdoux H (2003) Cannabis use and anxiety in daily life: a naturalistic investigation in a non-clinical population. Psychiatry Res 118:1-8

Trezza V, Vanderschuren LJ (2008a) Bidirectional cannabinoid modulation of social behavior in adolescent rats. Psychopharmacology (Berl) 197:217-227

Trezza V, Vanderschuren LJ (2008b) Cannabinoid and opioid modulation of social play behavior in adolescent rats: differential behavioral mechanisms. Eur Neuropsychopharmacol 18:519-530

Trezza V, Campolongo P, Cassano T, Macheda T, Dipasquale P, Carratu MR, Gaetani S, Cuomo V (2008a) Effects of perinatal exposure to delta-9-tetrahydrocannabinol on the emotional reactivity of the offspring: a longitudinal behavioral study in Wistar rats. Psychopharmacology (Berl) 198:529-537

Trezza V, Cuomo V, Vanderschuren LJ (2008b) Cannabis and the developing brain: insights from behavior. Eur $\mathrm{J}$ Pharmacol 585:441-452

Tsou K, Brown S, Sanudo-Pena MC, Mackie K, Walker JM (1998) Immunohistochemical distribution of cannabinoid CB1 receptors in the rat central nervous system. Neuroscience 83:393-411

Vardaris RM, Weisz DJ, Fazel A, Rawitch AB (1976) Chronic administration of delta-9-tetrahydrocannabinol to pregnant rats: studies of pup behavior and placental transfer. Pharmacol Biochem Behav 4:249-254

Vela G, Martin S, Garcia-Gil L, Crespo JA, Ruiz-Gayo M, Javier Fernandez-Ruiz J, Garcia-Lecumberri C, Pelaprat D, Fuentes JA, Ramos JA, Ambrosio E (1998) Maternal exposure to delta9tetrahydrocannabinol facilitates morphine self-administration behavior and changes regional binding to central $\mathrm{mu}$ opioid receptors in adult offspring female rats. Brain Res 807:101-109

Viveros MP, Marco EM, File SE (2005) Endocannabinoid system and stress and anxiety responses. Pharmacol Biochem Behav 81:331-342

Vorhees CV (1989) Concepts in teratology and developmental toxicology derived from animal research. Ann N Y Acad Sci 562:31-41

Wachtel SR, ElSohly MA, Ross SA, Ambre J, de Wit H (2002) Comparison of the subjective effects of Delta(9)-tetrahydrocannabinol and marijuana in humans. Psychopharmacology (Berl) 161:331-339

Ward IL, Weisz J (1984) Differential effects of maternal stress on circulating levels of corticosterone, progesterone, and testosterone in male and female rat fetuses and their mothers. Endocrinology 114:1635-1644

Weidenfeld J, Feldman S, Mechoulam R (1994) Effect of the brain constituent anandamide, a cannabinoid receptor agonist, on the hypothalamo-pituitary-adrenal axis in the rat. Neuroendocrinology 59:110-112

Witkin JM, Tzavara ET, Nomikos GG (2005) A role for cannabinoid CB1 receptors in mood and anxiety disorders. Behav Pharmacol $16: 315-331$ 